\title{
Influence of material characteristics of concrete and thermal insulation on the service life of exterior renders
}

\author{
J. Maděra ${ }^{1}$, V. Kočí ${ }^{1}$, E. Vejmelková ${ }^{1}$, R. Černý ${ }^{1}$, P. Rovnaníková ${ }^{2}$, \\ M. Ondráček ${ }^{3} \&$ M. Sedlmajer ${ }^{3}$ \\ ${ }^{1}$ Czech Technical University in Prague, Faculty of Civil Engineering, \\ Department of Materials Engineering and Chemistry, Czech Republic \\ ${ }^{2}$ Brno University of Technology, Faculty of Civil Engineering, \\ Institute of Chemistry, Czech Republic \\ ${ }^{3}$ Brno University of Technology, Faculty of Civil Engineering, \\ Institute of Technology of Building Materials and Components, \\ Czech Republic
}

\begin{abstract}
An assessment of the service life of exterior renders of building structures using combined computational-experimental approach is presented in the paper. In the experimental part, durability of selected renders and concretes is determined in terms of their frost resistance. A diffusion-type model is used for the description of coupled heat and moisture transport aimed at the identification of the number of frost cycles in a real structure. The computational implementation of the model leads to a system of two non-linear partial differential equations with the moisture accumulation function as additional condition. In a practical application of the model, a concrete wall provided with exterior thermal insulation system and both exterior and interior renders is analyzed. The influence of different material composition of building envelope in the service life of exterior renders is analyzed to meet the main objective of the paper. Different types of concrete, thermal insulation materials and renders are under consideration. Conclusions on the most advantageous material composition with respect to the service life of exterior renders are drawn.
\end{abstract}

Keywords: computational analysis, coupled heat and moisture transport, concrete wall, thermal insulation system. 


\section{Introduction}

Degradation of exterior renders is caused by many factors. The most principal are chemical and mechanical corrosion. As a mechanical corrosion we can assume the influence of weather conditions, particularly the destruction effect of freezing water which is contained in the exterior renders. Phase conversion of this water goes along with volume increase and this is the main mechanism leading to material destruction.

Different exterior render can be frost-resistant in varying degrees which depends on its material characteristics. The frost resistance could be defined by experimental methods.

However, more complicated is to determine the amount of freezing cycles which arise during the year in the investigated exterior render applied on real building structure. Freezing cycle can appear only when two conditions are met. The first condition is the presence of overhygroscopic (liquid) moisture, the second a temperature below water freezing point. So we have to observe the hygrothermal performance of the exterior render and compare the thermal and hygric state in parallel. Computational analysis is the best instrument for this operation. The amount of freezing cycles depends in the first instance on climatic conditions and material composition used in building envelope.

Based on experimental and computational results we can then design optimal material composition of building envelope with respect to its service life.

\section{Experimental}

Determination of frost resistance of exterior renders' materials and concretes was accomplished under laboratory conditions. For renders, the specimens in size of $40 \times 40 \times 160 \mathrm{~mm}$ were made, for concretes $100 \times 100 \times 400 \mathrm{~mm}$. Temperature in the laboratory was $21 \pm 1^{\circ} \mathrm{C}$, relative humidity was $45 \pm 5 \%$.

Water saturated specimens of renders - lime-cement plaster (LCP) and hydrophobic lime plaster modified by metakaolin (LPMH) - were cyclically frosted and defrosted until their damage got obvious. One frosting and defrosting cycle meant to put the specimens into plastic bag and then into freezing box for 6 hours, after removal to keep the specimens in laboratory with temperature of $20 \pm 1^{\circ} \mathrm{C}$ for 2 hours and then to put the specimens into the water for 16 hours. These cycles were repeated until the damage of specimens was visible. Damage of LPMH specimens is shown on Figure 1.

Table 1: $\quad$ Number of freezing cycles causing damage of material.

\begin{tabular}{|c|c|c|c|c|c|c|}
\hline & LCP & LPMH & CF & CM & CS & CR \\
\hline Number of freezing cycles & $>103$ & 40 & $>$ & $>100$ & $>$ & $>$ \\
& & & 100 & & 100 & 100 \\
\hline
\end{tabular}

Frost resistance tests of concretes - concrete modified by fly ash (CF), metakaolin (CM), slag (CS) and reference concrete without any modification (CR) - were carried out according to ČSN 73 1322/Z1:1968 [1]. The samples 
were tested after 28 days of concrete maturing and standard curing. The total test required 100 freezing and thawing cycles. One cycle consisted of 4 hours freezing at $-20^{\circ} \mathrm{C}$ and 2 hours thawing in $20^{\circ} \mathrm{C}$ warm water.

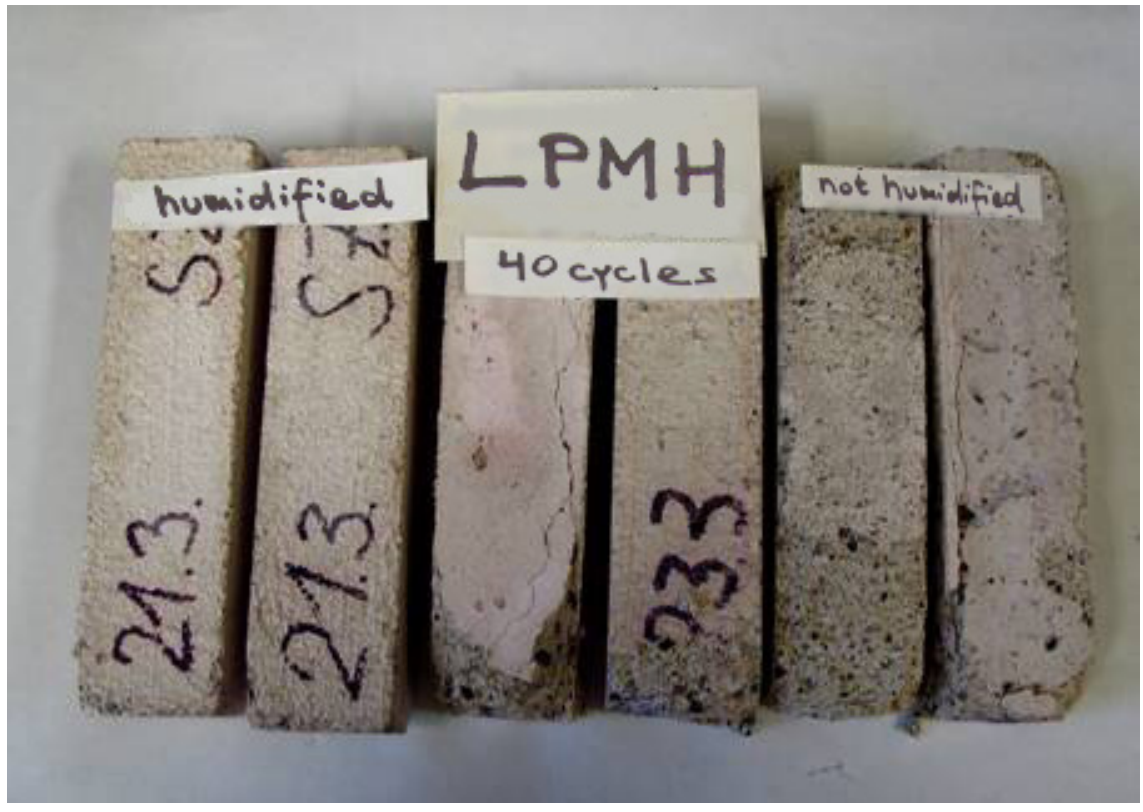

Figure 1: Hydrophobic lime plaster modified by metakaolin after 40 freezing cycles.

\section{Computational}

\subsection{Description of construction}

In this paper we assumed concrete wall made from different types of concrete (CF, CM, CS or CR) provided by thermal insulation system (EPS or mineral wool). The wall is provided by lime-cement plaster on interior side and by modified lime plaster on exterior side. By the same token we assumed the cases when the thermal insulation system is not present. To compare different hygrothermal behaviour of concrete in dependence on its modification we made simulation of simple concrete wall only. The material combination is shown in Figure 2.

Hygrothermal performance was investigated in exterior plaster in a point just under the surface and in concrete in a point close to the interface with render.

\subsection{Input parameters}

As the input parameters we need to know characteristics of used materials, boundary and initial conditions. 


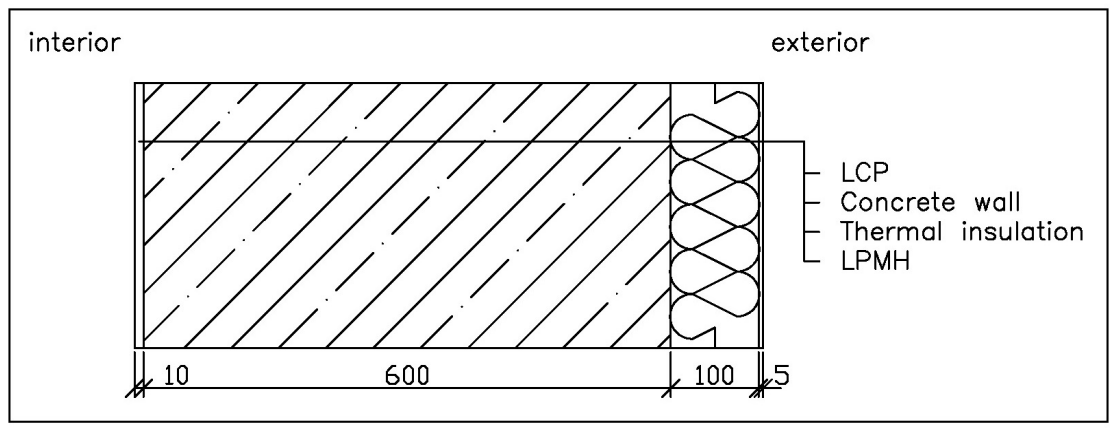

Figure 2: $\quad$ Scheme of building envelope.

Table 2: $\quad$ Basic material characteristics of concretes.

\begin{tabular}{|l|c|c|c|c|}
\hline & CF & CM & CS & CR \\
\hline \hline$\rho\left[\mathrm{kg} / \mathrm{m}^{3}\right]$ & 2356 & 2366 & 2334 & 2380 \\
\hline$\psi[\%]$ & 12.5 & 13.0 & 9.7 & 12.3 \\
\hline $\mathrm{c}[\mathrm{J} / \mathrm{kgK}]$ & 692 & 728 & 720 & 672 \\
\hline$\mu_{\text {dry cup }}[-]$ & 44.63 & 32.44 & 17.70 & 15.80 \\
\hline$\mu_{\text {wet cup }}[-]$ & 17.18 & 20.99 & 8.99 & 6.60 \\
\hline$\lambda_{\text {dry }}[\mathrm{W} / \mathrm{mK}]$ & 1.550 & 1.565 & 1.632 & 1.660 \\
\hline$\lambda_{\text {sat }}[\mathrm{W} / \mathrm{mK}]$ & 1.940 & 2.085 & 2.077 & 2.085 \\
\hline$\kappa\left[\mathrm{m}^{2} / \mathrm{s}\right]$ & $6.49 \mathrm{e}-9$ & $4.09 \mathrm{e}-9$ & $3.77 \mathrm{e}-9$ & $7.15 \mathrm{e}-9$ \\
\hline $\mathrm{W}_{\text {hyg }}\left[\mathrm{m}^{3} / \mathrm{m}^{3}\right]$ & 0.074685 & 0.106943 & 0.089000 & 0.083300 \\
\hline
\end{tabular}

Table 3: $\quad$ Basic material characteristics of plasters.

\begin{tabular}{|l|c|c|}
\hline & LCP & LPMH \\
\hline \hline$\rho\left[\mathrm{kg} / \mathrm{m}^{3}\right]$ & 1550 & 1745 \\
\hline$\psi[\%]$ & 40 & 33 \\
\hline $\mathrm{c}[\mathrm{J} / \mathrm{kgK}]$ & 1200 & 610 \\
\hline$\mu[-]$ & 7 & 10 \\
\hline$\lambda_{\text {dry }}[\mathrm{W} / \mathrm{mK}]$ & 0.700 & 0.845 \\
\hline$\lambda_{\text {sat }}[\mathrm{W} / \mathrm{mK}]$ & 2.40 & 2.40 \\
\hline$\kappa\left[\mathrm{m}^{2} / \mathrm{s}\right]$ & $7.3 \mathrm{e}-7$ & $3.9 \mathrm{e}-8$ \\
\hline $\mathrm{w}_{\mathrm{hyg}}\left[\mathrm{m}^{3} / \mathrm{m}^{3}\right]$ & 0.040 & 0.024 \\
\hline
\end{tabular}

Basic material characteristics of analyzed materials are shown in Tables 2, 3 and 4. We used following symbols: $\rho$ - bulk density $\left[\mathrm{kg} / \mathrm{m}^{3}\right], \psi-$ porosity [\%], $c$ - specific heat capacity $[\mathrm{J} / \mathrm{kgK}], \mu$-water vapour diffusion resistance factor $[-]$, $\lambda_{d r y}-$ thermal conductivity in dry conditions $[\mathrm{W} / \mathrm{mK}], \lambda_{\text {sat }}-$ thermal conductivity in water saturated conditions $[\mathrm{W} / \mathrm{mK}], \kappa$ - moisture diffusivity $\left[\mathrm{m}^{2} / \mathrm{s}\right], w_{\text {hyg }}-$ hygroscopic moisture content by volume $\left[\mathrm{m}^{3} / \mathrm{m}^{3}\right]$. All these parameters were 
measured in laboratory of transport processes at the Department of Materials Engineering and Chemistry, Faculty of Civil Engineering, Czech Technical University in Prague [2-3].

Table 4: $\quad$ Basic material characteristics of thermal insulation materials.

\begin{tabular}{|l|c|c|}
\hline & EPS & Mineral wool \\
\hline \hline$\rho\left[\mathrm{kg} / \mathrm{m}^{3}\right]$ & 50 & 170 \\
\hline$\psi[\%]$ & 97 & 89 \\
\hline $\mathrm{c}[\mathrm{J} / \mathrm{kgK}]$ & 1300 & 840 \\
\hline$\mu[-]$ & 50 & 3 \\
\hline$\lambda_{\text {dry }}[\mathrm{W} / \mathrm{mK}]$ & 0.040 & 0.055 \\
\hline$\lambda_{\text {sat }}[\mathrm{W} / \mathrm{mK}]$ & 0.560 & 1.200 \\
\hline$\kappa\left[\mathrm{m}^{2} / \mathrm{s}\right]$ & $2.1 \mathrm{e}-11$ & $5.1 \mathrm{e}-10$ \\
\hline $\mathrm{W}_{\mathrm{hyg}}\left[\mathrm{m}^{3} / \mathrm{m}^{3}\right]$ & 0.001 & 0.0073 \\
\hline
\end{tabular}

Initial and boundary conditions should be as realistic as possible. Therefore, we used climatic data in exterior for Prague in the form of a Test Referent Year (TRY), which contains average climatic data for 30 years. On interior side we used constant value of relative humidity $55 \%$ and temperature $21^{\circ} \mathrm{C}$.

The simulation started on 1 July and was done for 5 years.

\subsection{Computational model}

The computations were accomplished by the computational program TRANSMAT 7.1, which was developed at the Department of Material Engineering and Chemistry, Faculty of Civil Engineering, Czech Technical University in Prague on the basis of the general finite element package SIFEL. The mathematical formulation of coupled transport of heat and moisture leads to a system of partial differential equations, which are solved by finite element method. In the particular case in this paper, Künzel's model was used [4]:

$$
\begin{gathered}
\frac{d \rho_{v}}{d \varphi} \frac{\partial \varphi}{\partial t}=\operatorname{div}\left[D_{\varphi} \operatorname{grad} \varphi+\delta_{p} \operatorname{grad}\left(\varphi p_{s}\right)\right] \\
\frac{d H}{d T} \frac{\partial T}{\partial t}=\operatorname{div}(\lambda \operatorname{grad} T)+L_{v} \operatorname{div}\left[\delta_{p} \operatorname{grad}\left(\varphi p_{s}\right)\right]
\end{gathered}
$$

where $\rho_{v}$ is the partial density of moisture, $\varphi$ relative humidity, $\delta_{p}$ permeability of water vapour, $p_{s}$ partial pressure of saturated water vapour, $H$ enthalpy density, $L_{v}$ heat of evaporation, $\lambda$ thermal conductivity and $T$ temperature,

$$
D_{\varphi}=D_{w} \frac{d \rho_{v}}{d \varphi}
$$

is liquid moisture diffusivity coefficient, $D_{W}$ capillary transport coefficient. 


\subsection{Results of computational simulation}

The results are summarized in a set of figures. Every figure shows time dependence of moisture and temperature at the same time during fourth year of simulation. This is advantageous with regard to interpretation of simulation results. There are two horizontal lines in each figure which represent hygroscopic moisture content and temperature of freezing point.

From the vast number of figures produced in computational simulations only the most representative are chosen, rest of them is only described.

At the beginning, hygrothermal properties of simple concrete wall are analyzed. This allows us to get real image about differences in hygrothermal behaviour of different types of concrete in dependence of their modifications. Analysis of other building envelopes then follows which utilizes the previous knowledge.

\subsubsection{Simple concrete wall}

The most predisposed type of concrete to creation of freezing cycles is the reference concrete. However, due to low moisture content during the studied period there is not any freezing cycle. As we can see on Figure 3, overhygroscopic moisture content is reached only in summer month when the temperature is above zero.

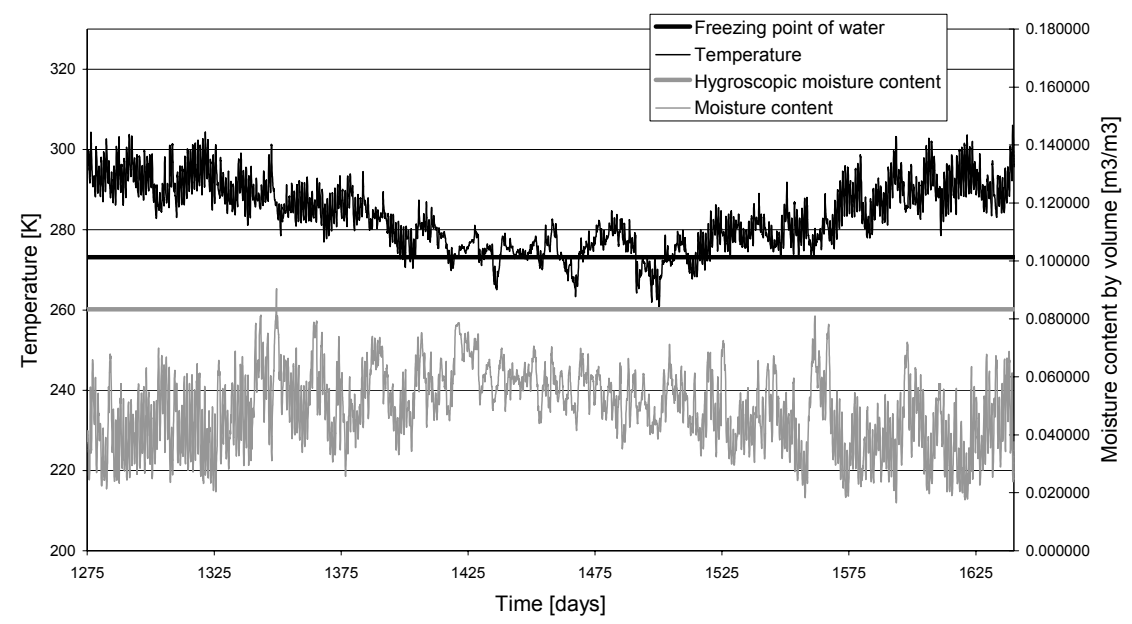

Figure 3: Hygrothermal performance of concrete, simple concrete wall (CR), $2 \mathrm{~mm}$ under the surface.

In concrete modified by fly ash, the overhygroscopic moisture content is reached once per a reference year, but as in the previous case this happens in summer month so there are not any possibilities of creation of freezing cycles.

In other types of concrete the overhygroscopic moisture content is not reached at all. 


\subsubsection{Concrete wall without thermal insulation system}

If we consider concrete wall provided only by plasters, the worst material combination is to use reference concrete without any modifications. This material combination leads to creation of two freezing cycles in exterior plaster. The cycles took 2 and 13 hours and arisen in $325^{\text {th }}$ and $326^{\text {th }}$ day of reference year (Figure 4). Other types of concrete do not give suitable conditions for freezing of water.

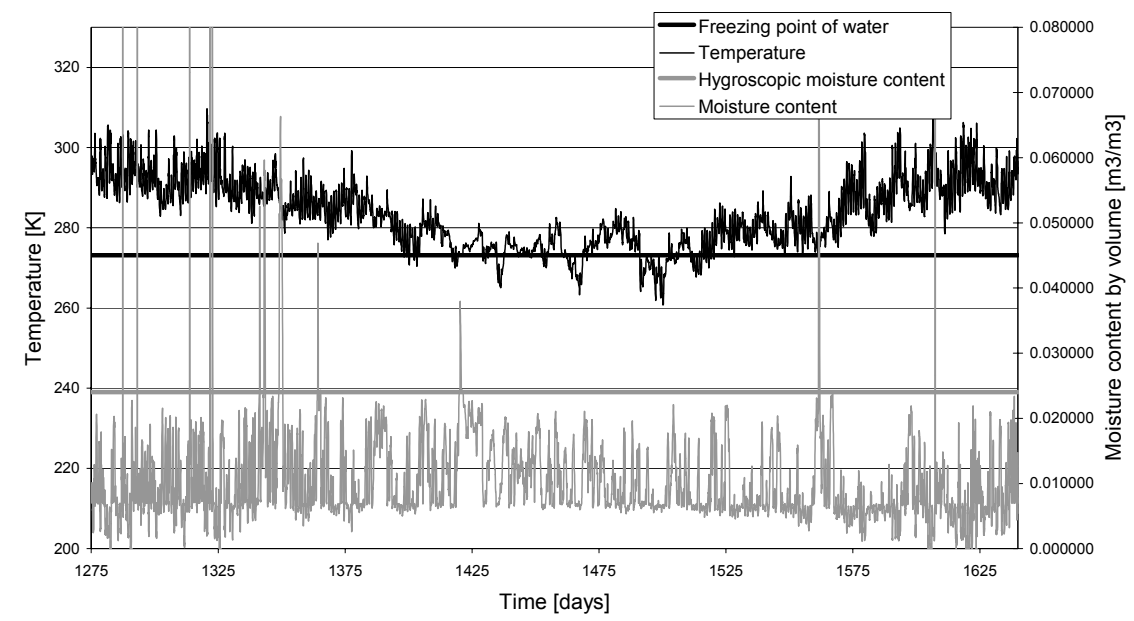

Figure 4: Hygrothermal performance of exterior plaster, concrete wall (CR) provided by exterior plaster, $2 \mathrm{~mm}$ under the surface.

In all cases, the water contained in concrete does not get frozen. All the results are similar to result on Figure 5.

\subsubsection{Concrete wall provided with thermal insulation system}

EPS as the insulation material provided with plaster reliably keeps the concrete wall from effects of freezing cycles no matter which type of concrete is under consideration.

Nevertheless, disadvantage of this material combination lies in abnormal strain of exterior plaster caused by weather conditions. In the simulation we counted more than 25 freezing cycles in every material combination in exterior plaster per reference year (Figure 6).

Duration of freezing cycles is different. The longest one takes 36 hours, the shortest one only 1 hour. Single cycles are separated by tiny temperature or moisture fluctuations which raise their final number.

Mineral wool has the same effect as EPS and protects the concrete wall from increase of moisture content and decrease of temperature at the same time. This prevents water in the wall getting overhygroscopic and getting frozen. Anyway, exterior plaster applied on mineral wool is abnormally exposed too. The number of freezing cycles during one referent year is little bit smaller then in plaster 
applied on EPS and counting about 25 cycles in every material combination (Figure 7).

As we can see, the cycles are separated by tiny moisture and temperature fluctuations, too.

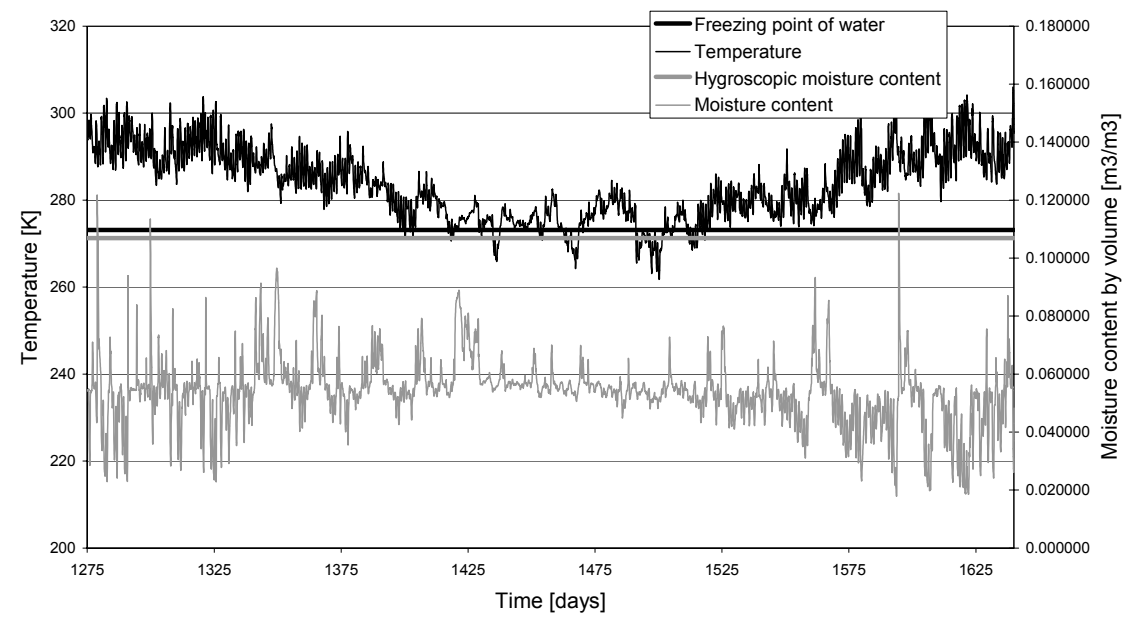

Figure 5: Hygrothermal properties of concrete, concrete wall (CM) provided by exterior plaster, $2 \mathrm{~mm}$ from material interface.

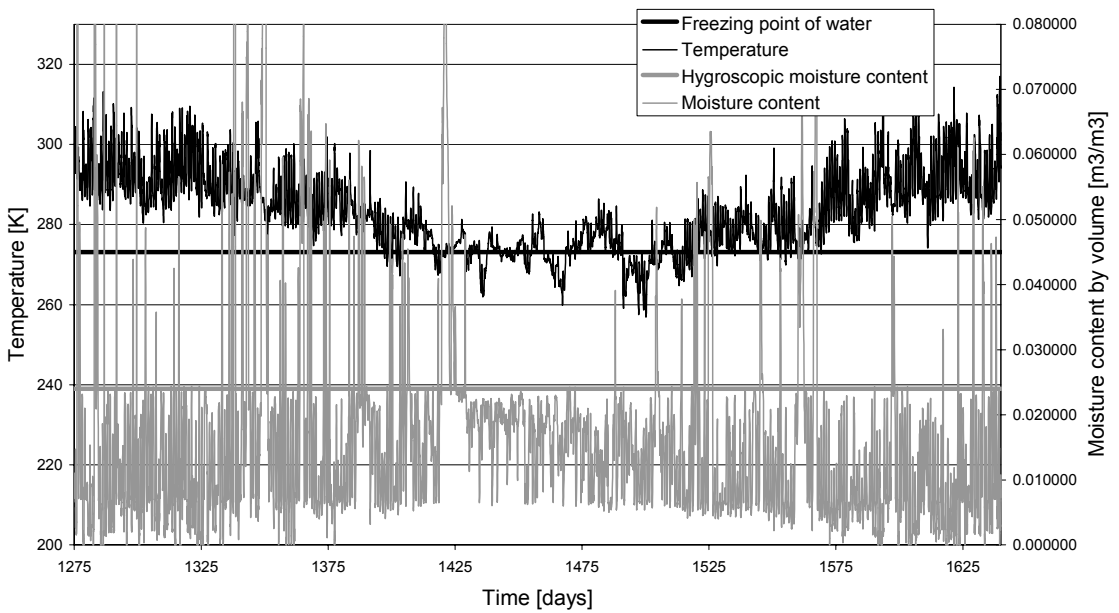

Figure 6: Hygrothermal performance in exterior plaster, concrete wall (CS) provided by EPS with exterior plaster, $2 \mathrm{~mm}$ under the surface. 


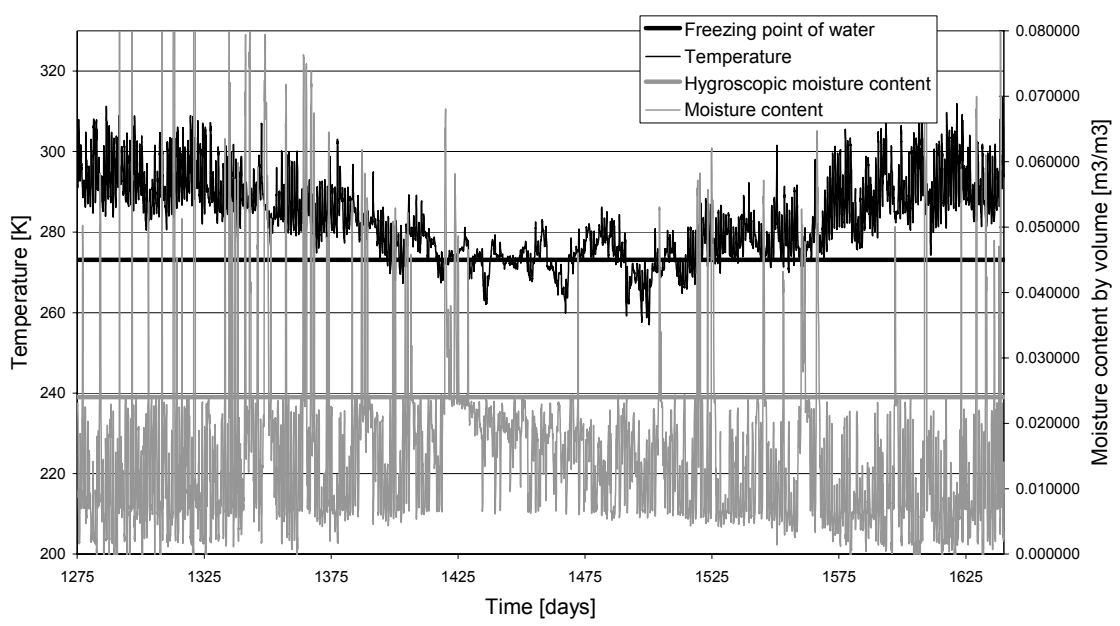

Figure 7: Hygrothermal performance in exterior plaster, concrete wall (CF) provided by mineral wool with exterior plaster, $2 \mathrm{~mm}$ under the surface.

\section{Discussion}

In an assessment of the impact of freezing cycles on service life of exterior renders, it is not enough to consider only the frost resistance determined in the laboratory. It is important to realize, that the number of freezing cycles depends on material combination, not only on material characteristics of used materials. As important as the freezing cycles' time is the lag between two cycles. If the freezing cycles' time is too short, water cannot solidify into ice and cannot disrupt the structure of plaster. By the same token, if the lag between two cycles is too short, ice cannot melt back into water and then refreeze again, so its destruction effect can be neglected and we can consider both as one.

When we evaluate the number of freezing cycles taking these considerations into account, we get new number of freezing cycles which is reduced (Table 5).

In this computer simulation only the liquid moisture appearance caused by rain was considered. However, there can be locations on building, which are exposed to water originating from other sources. This can be the case of a socle part of building and places with bad construction details solution. In these cases, the number of freezing cycles during one year could be much higher.

Although simple concrete wall built from all the types of investigated concrete does not show indications of freezing of the contained moisture, the wall made from reference concrete is very close to it. As we considered only reference year which is based on long-term average of relative humidity and temperature, the freezing cycles cannot be completely excluded in every particular year; in real weather conditions deviations from the average values may appear which could lead to creation of some freezing cycles. Basically, this 
Table 5: $\quad$ Number of freezing cycles after reduction.

\begin{tabular}{|c|c|c|c|c|c|c|c|c|}
\hline & LCP & $\mathrm{CF}$ & $\mathrm{CM}$ & $\mathrm{CS}$ & $\mathrm{CR}$ & EPS & MW & LPMH \\
\hline \multirow{4}{*}{ Simple concrete wall } & - & 0 & - & - & - & - & - & - \\
\hline & - & - & 0 & - & - & - & - & - \\
\hline & - & - & - & 0 & - & - & - & - \\
\hline & - & - & - & - & 0 & - & - & - \\
\hline \multirow{4}{*}{$\begin{array}{l}\text { Concrete wall } \\
\text { provided with exterior } \\
\text { plaster }\end{array}$} & 0 & 0 & - & - & - & - & - & 0 \\
\hline & 0 & - & 0 & - & - & - & - & 0 \\
\hline & 0 & - & - & 0 & - & - & - & 0 \\
\hline & 0 & - & - & - & 0 & - & - & 2 \\
\hline \multirow{4}{*}{$\begin{array}{l}\text { Concrete wall } \\
\text { provided with EPS and } \\
\text { exterior plaster }\end{array}$} & 0 & 0 & - & - & - & 0 & - & 20 \\
\hline & 0 & - & 0 & - & - & 0 & - & 20 \\
\hline & 0 & - & - & 0 & - & 0 & - & 19 \\
\hline & 0 & - & - & - & 0 & 0 & - & 20 \\
\hline \multirow{4}{*}{$\begin{array}{l}\text { Concrete wall } \\
\text { provided with mineral } \\
\text { wool and exterior } \\
\text { plaster }\end{array}$} & 0 & 0 & - & - & - & - & 0 & 20 \\
\hline & 0 & - & 0 & - & - & - & 0 & 21 \\
\hline & 0 & - & - & 0 & - & - & 0 & 19 \\
\hline & 0 & - & - & - & 0 & - & 0 & 21 \\
\hline
\end{tabular}

is caused by the lowest value of moisture diffusivity of reference concrete which does not allow for a relatively fast release of contained moisture.

Considering the wall provided with exterior plaster only, the reference concrete gives us the worst results again. There are some freezing cycles in all types of concrete, however water contained in exterior plaster applied on reference concrete gets frozen twice a reference year. This determines the service life of plaster approximately to 15 years. In rest of cases, damage caused by weather conditions is not the main cause of degradation.

If we investigate concrete wall provided with thermal insulation system, namely EPS or mineral wool, due to propitious thermal insulating properties the temperature in the concrete will never drop below zero which makes freezing of water impossible. However, both materials of thermal insulation have very low value of moisture diffusivity. Therefore, the moisture cannot be transported to concrete in sufficient amount and its level remains relatively high for long time. Pull of low temperature causes then freezing of this water. Surface layer $(2 \mathrm{~mm})$ of exterior plaster will resist only for 2 years. But overall thickness of the plaster is $5 \mathrm{~mm}$, so the service life could be doubled.

\section{Conclusions}

Comparing all the results obtained in this paper, from the point of view of frost resistance the best option is to use concrete modified by fly ash. Although in most of cases, concrete is not the material which will be damaged by freezing of water, its type has still relatively high influence on service life of other materials of the wall, renders in particular. 
Nowadays, most of concrete buildings are provided with thermal insulation. Based on results of this simulation, more advantageous is to use EPS, but the differences between EPS and mineral wool are not too high. So, the sole criterion of water freezing in the exterior render is not the decisive one for a choice of thermal insulation material.

\section{Acknowledgement}

This research has been supported by the Czech Science Foundation, under grant No 103/07/0034.

\section{References}

[1] ČSN 73 1322/Z1:1968 Concrete testing - Hardened concrete - Frost resistance. Czech Standardization Institute, Prague 2003.

[2] VEJMELKOVÁ, E. - ČERNÝ, R.: Application of Alternative Silicate Binders in the Production of High Performance Materials Beneficial to the Environment. In: Proceedings of the 2008 World Sustainable Building Conference [CD-ROM]. Balnarring, Victoria: ASN Events Pty Ltd, 2008, pp. 520-525.

[3] PERNICOVÁ, R. - PAVLÍKOVÁ, M. - PAVLÍK, Z. - ČERNÝ, R.: Vliv metakaolinu na mechanické, tepelné a vlhkostní vlastnosti vápenných omitek. In: Metakaolin 2007. Brno: VUT FAST, 2007, pp 70-77.

[4] KÜNZEL, H.M.: Simultaneous Heat and Moisture Transport in Building Components, Ph.D. Thesis. IRB Verlag, Stuttgart, 1995. 